\title{
Altıntaş Köyü (Uşak) Kuzeyindeki Andezitik Kayaçların Kaplama ve Döşeme Taşı Olarak Kullanılabilirliğinin Araştırılması
}

\author{
Ebru BAŞPINAR TUNCAY*, Deniz DEDEOĞLU, Fuzuli YAĞMURLU \\ Süleyman Demirel Üniversitesi, Mühendislik Fakültesi, Isparta \\ Geliş Tarihi (Received): 29.02.2016, Kabul Tarihi (Accepted): 13.04.2016 \\ $\square$ Sorumlu Yazar (Corresponding author): ebrubaspinar@sdu.edu.tr \\ (6) +902462111301 回+902463270859
}

\section{Öz}

Mağmatik kökenli kayaçlar sınıfında yer alan andezitler (andezit ve andezitik kayaçlar), sağlam olmasından dolayı Türkiye'de genellikle dış kaplama ve yer döşemesi olarak kullanılmaktadır. Türkiye'de andezit ve türevleri olan kayaçlar Afyon, Ankara, Denizli, Balıkesir, Uşak illerinde yaygın olarak bulunur. Çalışmanın konusunu oluşturan Uşak yöresindeki andezit ocağı, Altıntaş köyünün kuzeyinde bulunur ve Uşak belediyesi tarafından işletilmektedir. Çalışma alanında bulunan birimler alttan üste doğru sırayla Miyosen yaşlı Hacıbekir grubuna ait Yeniköy formasyonu, Yeniköy formasyonunu kesen Karaboldere volkanitleri Pliyosen yaşlı İnay grubuna ait Ulubey formasyonu, Kuvaterner yaşlı Asartepe formasyonu ve alüvyonla temsil edilmektedir. Bu çalışmada Karaboldere volkanikleri içerisinde yer alan andezitik kayaçlar, gri ve pembemsi olmak üzere iki renk olarak incelenmiştir. Her iki kayacın mineralojikpetrografik ve jeokimyasal özellikleri belirlenmiştir. Kayaçların ortalama $\mathrm{SiO}_{2}, \mathrm{Al}_{2} \mathrm{O}_{3}$ ve $\mathrm{Fe}_{2} \mathrm{O}_{3}$ içeriği \%57.03-57,29, \%15.14-15.11 ve \% 6.03-6.12'dir. Toplam alkali-SiO 2 (Le Bas vd., 1986) ve Nb/Y (Winchester ve Floyd, 1977) diyagramlarına göre kayaçlar, kimyasal bileşim bakımından trakiandezit alanına düşmektedir. Çalışmanın konusunu oluşturan kayaçların fiziko-mekanik özellikleri (yoğunluk, gözeneklilik, su emme oranı, basınç dayanımı, dinamik elastisite modülü vs.) TSE ve ISRM standartlarında belirtilen deney yöntemlerine göre belirlenmiştir. Bu çalışma sonucunda elde edilen veriler, hem UP hem de UG kayacılarının kaplama taşı olarak kullanılabileceğini göstermektedir.

Anahtar Kelimeler: Altıntaş, trakiandezit, eğilme dayanımı, aşınma dayanımı, kaplama taşı

\section{Investigation of Avability of the Andesitic Rocks in the North of Altıntaş Village (Uşak) as a Covering and Laying Stone}

\begin{abstract}
Andesites (andesite and andesitic rocks) which are magmatic origin are usually used as outer coating and flooring because of their hardness in Turkey.In Turkey, andesite and derivatives of andesitic rocks extensively take place at Afyon, Ankara, Denizli, Balıkesir and Uşak. Andesite quarry at Uşak area, which is the subject of this study, is Iocated north of Altıntaş village and is operated by municipality of Uşak. Units in the study area from the bottom to the up are represented by Miocene aged Yeniköy formationof Hacıbekir group, Karaboldere volcanics cutting Yeniköy formation, Pliocene aged Ulubey formation of Inay group, Quaternary aged Asartepe formation and alluvion. In this study, andesitic rocks in Karaboldere volcanics were examined as gray and pinkish. The mineralogical-petrological
\end{abstract}


and geochemical characteristics of both of them are determined. Andesitic rocks' $\mathrm{SiO}_{2}, \mathrm{Al}_{2} \mathrm{O}_{3}$ and $\mathrm{Fe}_{2} \mathrm{O}_{3}$ contents are averagely $57.03-57.29 \mathrm{wt} \%, 15.14-15.11 \mathrm{wt} \%$ and 6.02-6.12 wt\%. According to the total alkali-SiO $\mathrm{S}_{2}$ (Le Bas et al., 1986) and $\mathrm{Nb} / \mathrm{Y}$ (Winchester and Floyd, 1977) diagrams, rocks plot into the trachyandesite field. Physicomechanical properties (density, porosity, water absorption rate, compressive strength, dynamic modulus of elasticity etc.) of rocks, which are the subject of this study, have been investigated according to TSE standards and ISRM testing method. The overall datas obtained from this study suggest that both UP and UG rocks can be used as coating stone.

Keywords: Altıntaş, Trachyandesite, Bending strength, Abrasion resistance, Coating Stone

\section{GiRiş}

Ticari olarak işletilebilen doğal taşlar, geçmişte ve günümüzde yaygın olarak kullanılan yapı malzemeleridir. Dünyada ve ülkemizde yapı malzemesi olarak doğal taşların kullanımı, inşaat sektöründeki yatırımlarla ve gelişmelerle birlikte yaygınlaşmış ve doğal taşlara olan talep artmıştır. 2013 yılı doğal taş verilerine göre Çin, İtalya, Hindistan, Brezilya ve Türkiye önemli ihracatçı ülkelerdir.

Türkiye'de farklı renk ve özelliklerde mermer, kalker, oniks, konglomera, breş ve magmatik kökenli kayaçlar (granit, siyenit, diyabaz, diyorit, serpantin, vb.) bulunmaktadır. Dünyada tercih edilebilir kalitede ve nitelikte doğal taş çeşidine sahip olan Türkiye'de, Ege Bölgesi \%32, Marmara \%26, İç Anadolu \%11, Doğu Anadolu Güneydoğu Anadolu, Karadeniz ve Akdeniz Bölgesi \%31 doğal taş rezervine sahiptir (T.C Ekonomi Bakanlığı, 2012).

Mağmatik kökenli kayaçlar, mermerden sonra ikinci öneme sahip doğal taşlardır. Granit, bazalt, andezit vb., genellikle iç, dış kaplama ve zemin döşemesinde kullanılmaktadır. Gelişmiş ülkelerde, inşaat sektöründe kullanılan bu gruptaki kayaçların tercih edilmesinde, iyi cila alma, renk albenisi, dayanıklıığı, parlaklığı gibi özellikleri uzun yıllardır dikkate alınırken, ülkemizde bu olgu son zamanlarda yaygınlaşmaya başlamıştır (T.C. Ekonomi Bakanlığı, 2012). Bu grupta yer alan andezitler veya andezitik kayaçlar, teknolojinin gelişmesi ile parlatılabilen kayaçlar sınıfında hem mermer, hem de sert taş olarak nitelendirilmektedir. Bu kayaçlar, genellikle kaldırım, bordür, parke taşı, kaplama taşları, merdiven basamakları, istinat duvarları, kent mobilyaları, tarihi bina ve alanların yenilenmesi ve mezar taşları olarak kullanılmaktadır.

Enerji ve Tabi kaynaklar Bakanlığı verilerine göre Türkiye'de andezit üretim değerleri Tablo 1'de verilmiştir (İC Danışmanlık ve Eğitim, 2014). Andezit üretimi 517.831 ton üretimiyle 2005 yılında ivme kazanmıştır. 2010 yılında andezitin üretimi en fazladır (6.436.380 ton).
Tablo 1. Yıllara göre üretim miktarları (iC Danışmanlık ve Eğitim, 2014)

\begin{tabular}{|c|c|}
\hline YII & Üretim Miktarı (ton) \\
\hline 2003 & 80.605 \\
\hline 2004 & 81.900 \\
\hline 2005 & 517.831 \\
\hline 2006 & 2.485 .956 \\
\hline 2007 & 4.115 .184 \\
\hline 2008 & 3.307 .107 \\
\hline 2009 & 1.908 .544 \\
\hline 2010 & 6.436 .380 \\
\hline 2011 & 2.878 .093 \\
\hline 2012 & 2.873 .932 \\
\hline
\end{tabular}

Uşak yöresi ve civarında yapılan önceki çalışmalarda, Uşak Belediyesi tarafından işletilen ve Uşak andeziti olarak adlandırılan Karaboldere volkanikleri içerisinde yer alan andezitik kayaçların, jeolojisi (yayılımı, stratigrafik konumu, yaşı ve mineralojik bileşimi) incelenmiştir. Ancak Uşak yöresinde çalışma alanı dışında, geniş yayılım sahip kayacın fiziksel ve mekanik özellikleri ile ilgili ayrıntılı bir çalışma bulunmamaktadır.

Bu çalışma, Uşak Belediyesi tarafından işletilen ocaktan çıkarılan, kaplama ve döşeme taşı olarak kullanılan kayacın, fiziko-mekanik özellikleriyle ilgili kullanıcıya bilgi sunmaktadır. Ayrıca çalışma alanı dışında yörede geniş yayılıma sahip olan Karaboldere volkanikleri ile ilgili yapılabilecek çalışmalara ışık tutması öngörülmektedir.

Bu çalışmanın birinci bölümünde, bu andezitik kayaçlar, gri (UG) ve pembemsi (UP) olarak iki ayrı renkte incelenmiştir. Her iki kayacın, mineralojik-petrografik ve jeokimyasal özellikleri belirlenmiştir. İkinci bölümünde ise UG ve UP'nin fiziko-mekanik özelliklerini belirlemek için, TSE ve ISRM standartlarında belirtilen deney metotlarına uygun olarak deneyler yapılmıştır. Son bölümde ise yapılan deneylerden elde edilen veriler yorumlanmıştır.

\section{ÇALIŞMA ALANI}

Uşak Belediyesi tarafından halen işletilmekte olan ocak Uşak iline bağlı Altıntaş köyünün kuzeyinde bulunmaktadır. Uşak iline $18 \mathrm{~km}$ uzaklıkta olan ocağa ulaşım Mesu- 
diye köyü üzerinden asfalt bir yolla sağlanmaktadır (Şekil 1).

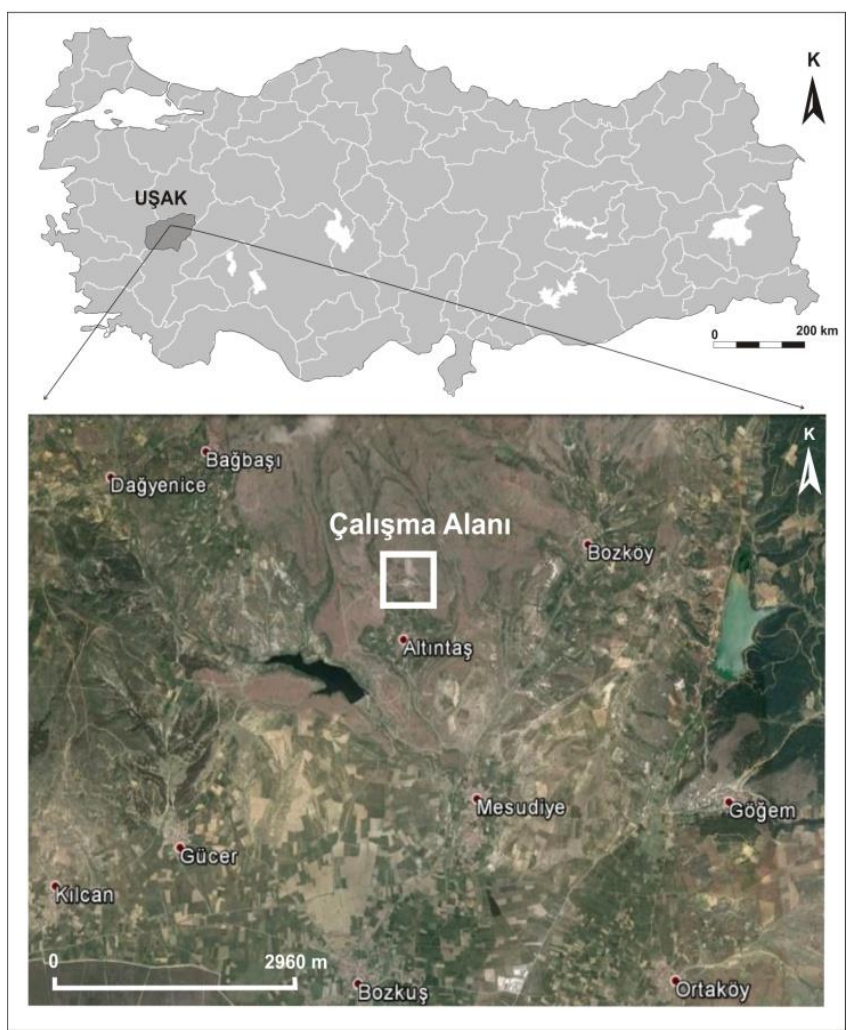

Şekil 1. Çalışma alanının yerbulduru haritası

Çalışmanın konusunu oluşturan Altıntaş köyü'nün kuzeyinde bulunan işletilmekte olan trakiandezit ocağı Şekil 2'de görülmektedir.

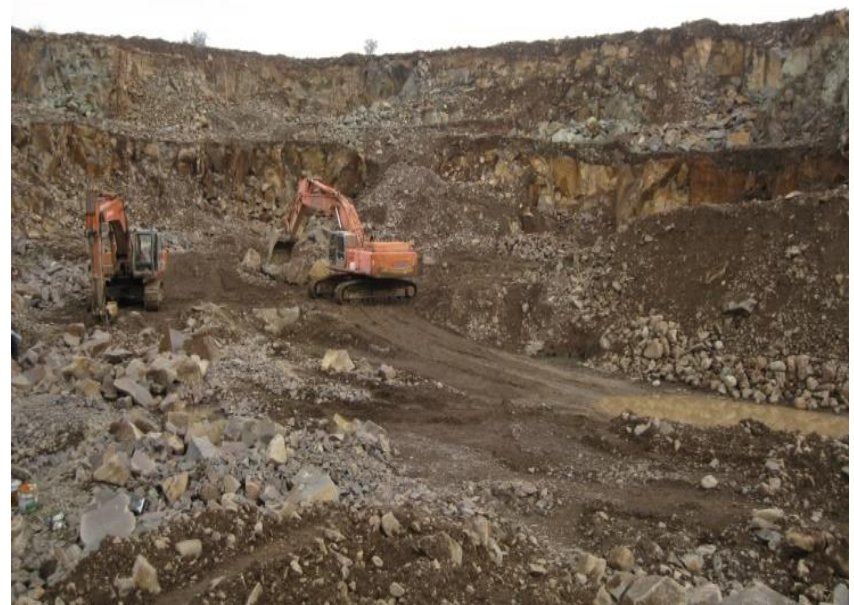

Şekil 2. Altıntaş trakiandezit ocağından görünüm

\section{MATERYAL VE YÖNTEM}

Bu çalışmada Karaboldere volkanikleri ait andezitik kayaçların 2 farklı renkte olduğu gözlenmiştir. Kayaçlar, Uşak gri (UG) ve Uşak pembemsi (UP) olarak isimlendirilerek, kayaçlardan mineraloji-petrografisini belirlemek için ince kesit yapılmıştır. Major, minor ve iz elementlerinin belirlenmesi için UP ve UG'den 3'er adet numune Acme Laboratuvarlarına (Kanada) gönderilmiştir.

İkinci olarak ise kayacın fiziko-mekanik özelliklerini belirlemek için ISRM ve TSE standartlarında belirtilen sayıda ve numune ebatlarına uygun boyutlandırılmış kayaç örneklerine Tablo 2'de belirtilen testler yapılmıştır (Şekil 3).

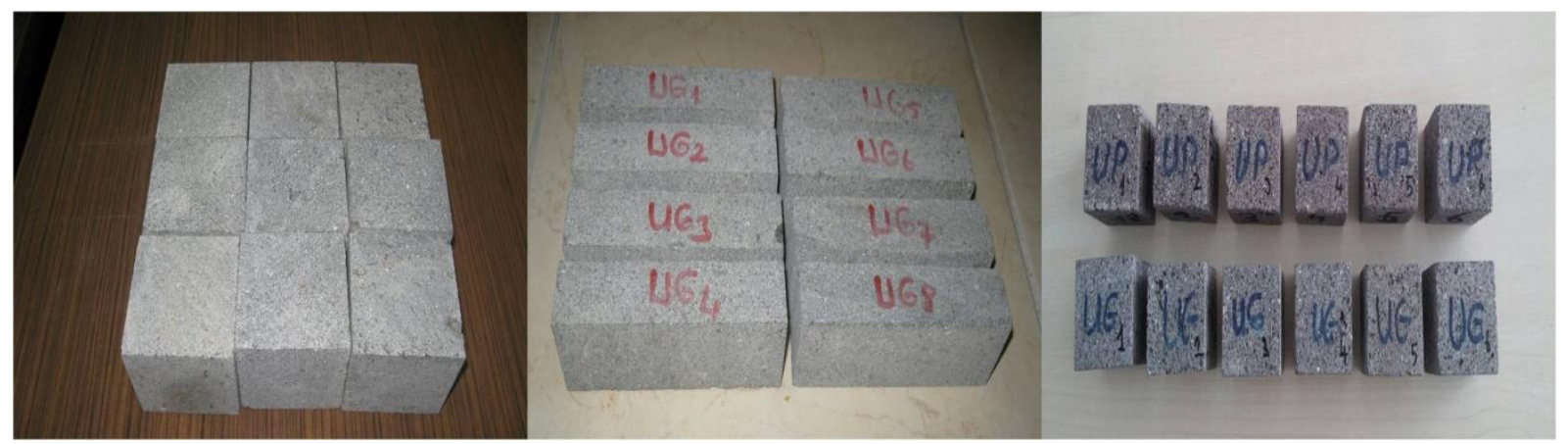

Şekil 3. Fiziko-mekanik deneylerde kullanılan boyutlandırılmış numuneler 
Tablo 2. Kayacın belirlenen fiziko-mekanik özellikleri

\begin{tabular}{|c|c|c|}
\hline Deney adı & Metot & $\begin{array}{l}\text { Standartta belirtilen Numune sayısı, } \\
\text { Numune boyutu }(\mathrm{mm}) \text { veya miktarı }(\mathrm{g})\end{array}$ \\
\hline Gerçek Yoğunluk ve Toplam Gözeneklilik & TS EN 1936 (2010) & En az 3 tekrar, $25 \mathrm{~g}$ \\
\hline Görünür yoğunluk ve Açık gözeneklilik & TS EN $1936(2010)$ & En az 6 adet, $50 * 50 * 50 \mathrm{~mm}$ \\
\hline Atmosfer basıncı altında su emme tayini & TS EN 13755 (2009) & En az 6 adet, $70 * 70 * 70 \mathrm{~mm}$ \\
\hline Tek eksenli basınç dayanımı tayini & TS EN 1926 (2013) & En az 6 adet, $70 * 70 * 70 \mathrm{~mm}$ \\
\hline Sabit moment altında eğilme dayanımı & $\begin{array}{c}\text { TS EN 13161 } \\
(2014)\end{array}$ & En az 10 adet, $150 * 50 * 25 \mathrm{~mm}$ \\
\hline Schmidt sertliği & Brown (1981) & En az 5 adet, $100^{*} 100^{*} 100 \mathrm{~mm}$ \\
\hline Aşınma direnci tayini (Böhme metodu) & TS EN 14175 (2014) & En az 6 adet, $71^{\star} 71^{\star} 71 \mathrm{~mm}$ \\
\hline Darbe dayanımı & TS $699(2009)$ & En az 6 adet, $50 * 50 * 50 \mathrm{~mm}$ \\
\hline Nokta yükleme & $\begin{array}{l}\text { Ulusay ve Hudson } \\
\text { (2007) }\end{array}$ & En az 10 adet, $150 * 50 * 25 \mathrm{~mm}$ \\
\hline Dinamik elastisite modülü & TS EN $14579(2006)$ & En az 3 adet, $70^{\star} 70^{\star} 70 \mathrm{~mm}$ \\
\hline Dinamik Poisson oranı & TS EN 14579 (2006) & En az 3 adet, $70^{\star} 70^{\star} 70 \mathrm{~mm}$ \\
\hline $\begin{array}{l}\text { Termal şok etkisiyle yıpranmaya direnc } \\
\text { tayini }\end{array}$ & TS EN14066 (2004) & $200 * 200 * 20 \mathrm{~mm}$ \\
\hline
\end{tabular}

\section{ARAŞTIRMA BULGULARI}

\section{Bölgesel Jeoloji}

Çalışma alanında en altta Miyosen yaşı Hacıbekir grubuna ait Yeniköy formasyonu (Thy) yeralır. Yeniköy formasyonu, çalışma alanının batısında Dağyenice Köyü, Karabalçık Tepe ve Külçe Tepe dolaylarında yayılımı gözlenmektedir (Şekil 3). Formasyon kirli sarı renkli konglomera, kumtaşı, kiltaşı, tüfit ve killi kireçtaşı ardalanmasından oluşur (Ercan vd., 1978). Birimin üzerinde Altıntaş, Güldezler, Bağbaşı köylerinin yakın çevresinde yayılım gösteren Karaboldere volkanitlerinin trakiandezit-andezit-tüf ve aglomeraları (Thkv2B) gözlenir. Altıntaş köyü kuzeyinde, Elmadağı Tepe, Büyükalan Mevki dolaylarında yayılım gösteren Karaboldere volkanitlerine ait Miyosen yaşlı trakiandezitik-andezitik lavlar (Thkv 2A), Yeniköy formasyonunu ve Karaboldere volkanitlerinin tüf ve aglomeralarını (Thkv2B) keser konumdadır [13]. Karaboldere volkanitleri üzerinde Mesudiye Köyü, Korukıran Mevki dolaylarında İnay grubu kapsamında Pliyosen yaşlı Ulubey formasyonu (Tiu) uyumsuz olarak gelir. Formasyon genelde yatay tabakalı, killi-marnlı ara seviyeler içeren gölsel kireçtaşlarından oluşur. Birim eş yaşı volkanizmadan etkilendiğinden, sıcak ve $\mathrm{SiO} 2$ yönünden doymuş eriyikler çökelmeye zaman zaman eşlik eder. Bu durum birim içinde yer yer silisleşmelere neden olur (Ercan vd., 1978).
Ulubey formasyonu (Tiu) üzerine uyumsuz olarak Kuvaterner yaşlı Asartepe formasyonu (Qat) gelir. Birim çalışma alanında Gücer Köyü, Kıran Tepe, Kırharman Tepe dolaylarında yayılım gösterir. Genelde kızılımsı renkli, gevşek yapılı, tüf ve kil çimentolu, orta-kalın tabakalı, yarı yuvarlak çakıllı konglomera-kumtaşı ardalanması şeklinde gözlenen birim akarsu çökelleridir. İnceleme aşanında gözlenen diğer birim ise Alüvyon (Qal)'dır. Alüvyon genellikle çalışma alanının güneyinde topoğrafyanın düzleştiği alanlarda ve dere yataklarında tutturulmamış kum, çakıl, kil şeklinde gözlenir (Ercan vd., 1978).

\section{Kayacın mineraloji-petrografisi ve jeokimyasal bile- şimi}

İnceleme alanındaki andezitik kayaçlar, bölgede gri (UG) ve pembemsi (UP) renklerde gözlenmektedir. Gri renkli kayaç, devitrifiye volkanik camdan oluşan hamur içerisinde, plajioklas (oligoklas, andezin), piroksen, amfibol, biyotit fenokristalleri içermektedir (Şekil 4). Ortaç bileşimli kayaç içerisinde feldispatlar ve ince saçınımlı gaz boşlukları mevcuttur. Apatit ve zirkon tali minerallerdir. Hamurda silisifiye, epidotlaşma, demiroksitleşme vardır.

Pembemsi renkli kayaç, gri renkli ile aynı dokusal ve mineralojik bileşime sahiptir. Fakat mafik mineral oranı daha fazla, demiroksitleşme daha çok ve mafik minerallerin etrafında demir sıvamaları mevcuttur. Biyotitlerin kenarlarında koyulaşma ve yer yer opaklaşmalar mevcuttur. 


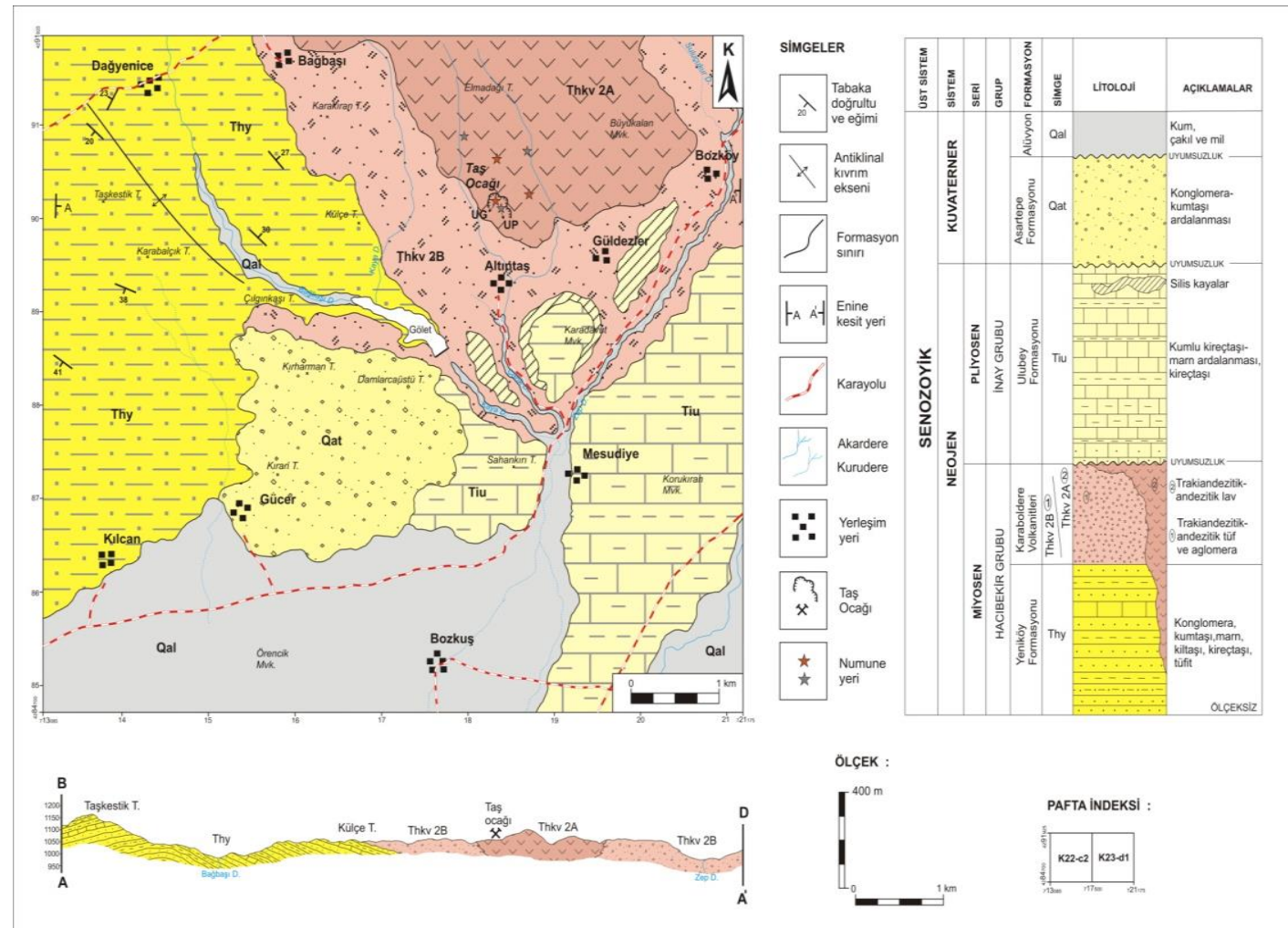

Şekil 3. Çalışma alanının jeolojik haritası, enine kesiti ve sütun kesiti (Ercan ve Dinçel, 1980'den değiştirilerek)
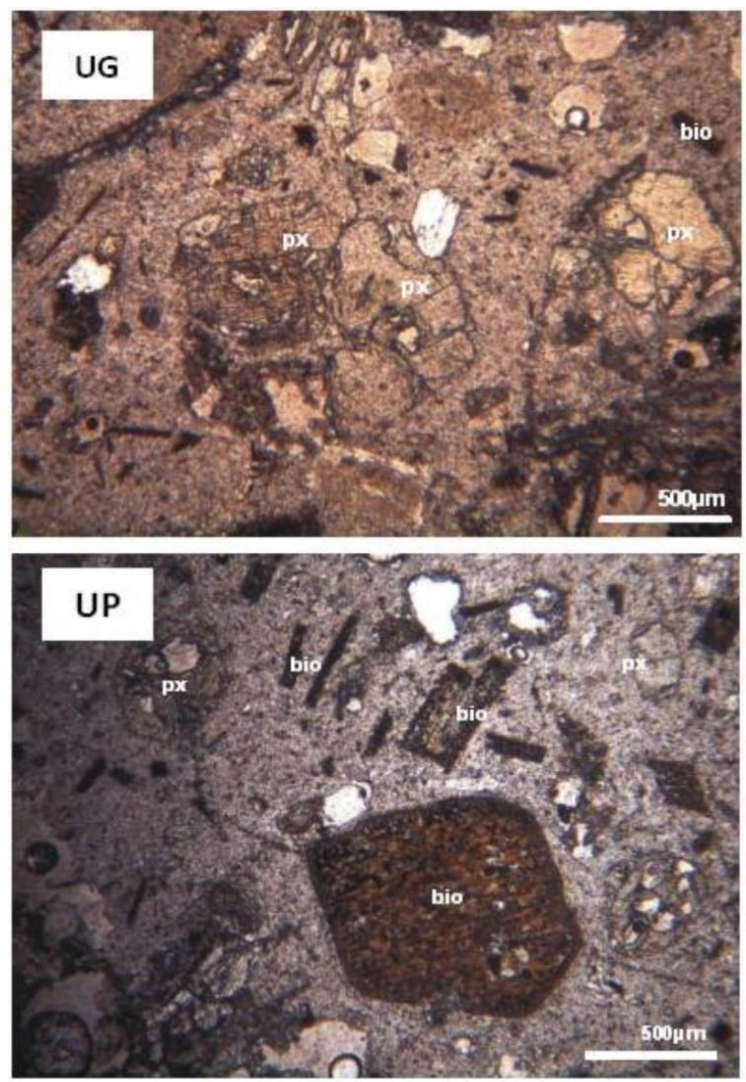

Şekil 4. UG'nin ince kesit görüntüleri (px: piroksen; bio: biyotit) 
Kayaçların majör, minör ve iz elementleri belirlenmiştir. Tablo 3'de kayaçların (UG) ve (UP) ortalama kimyasal analizleri verilmiştir. Bu sonuçlara göre $\mathrm{SiO}_{2}$ içerikleri her iki kayaçta \% 57 civarındadır. Ateşte kayıp değerleri \% 2.4-1.7 civarındadır. $\mathrm{Al}_{2} \mathrm{O}_{3}$ içeriği \% 15 ve $\mathrm{Fe}_{2} \mathrm{O}_{3}$ $\%$ 6'dır.

Tablo 3. Kayaçların (UP) ve (UG) ortalama kimyasal analizleri

\begin{tabular}{|c|c|c|}
\hline $\begin{array}{c}\text { Kimyasal Bile- } \\
\text { şim (\%) }\end{array}$ & UG & UP \\
\hline $\mathrm{SiO}_{2}$ & 57.03 & 57.29 \\
\hline $\mathrm{Al}_{2} \mathrm{O}_{3}$ & 15.14 & 15.11 \\
\hline $\mathrm{Fe}_{2} \mathrm{O}_{3}$ & 6.02 & 6.12 \\
\hline $\mathrm{MgO}$ & 3.41 & 3.78 \\
\hline $\mathrm{CaO}$ & 5.36 & 5.3 \\
\hline $\mathrm{Na}_{2} \mathrm{O}$ & 2.69 & 2.61 \\
\hline $\mathrm{K}_{2} \mathrm{O}$ & 5.64 & 5.66 \\
\hline $\mathrm{TiO}_{2}$ & 1.14 & 1.12 \\
\hline $\mathrm{P}_{2} \mathrm{O}_{5}$ & 0.62 & 0.64 \\
\hline $\mathrm{MnO}$ & 0.06 & 0.08 \\
\hline Ateşte Kayıp & 2.30 & 1.70 \\
\hline Toplam & 99.47 & 99.49 \\
\hline
\end{tabular}

Kayaçların kimyasal analizleri Toplam alkali-SiO2 diyagramına göre değerlendirildiğinde Trakiandezit alanına düşmektedir (Şekil 5). [17]'nın TAS diyagramında alkali karakterdeki Ta, Bta alanlarına düşen kayaçların alt sınıflamasına göre (Tablo 4) trakiandezit bölgesine düşen bu kayaçların latit karakterinde olduğu belirlenmiştir.

Bazı araştırmacılar TAS diyagramının kullanılmasında alterasyon nedeniyle artan $\mathrm{Na}$ ve $\mathrm{K}$ mobilitesi ve zenginleşen $\mathrm{SiO}_{2}$ 'den dolayı hassas olunması gerektiğini söylemişlerdir ((Hart vd. 1974; Humphris ve Morrison ,1978). Winchester ve Floyd (1978)'un $\mathrm{SiO}_{2}$ 'ye karşı $\mathrm{Nb} / \mathrm{Y}$ diyagramı (Şekil 6) ve $\mathrm{Nb} / \mathrm{Y}^{\prime}$ ye karşı $\mathrm{Zr} / \mathrm{TiO}_{2}$ diyagramı (Şekil 7) çizilmiştir. Buna göre diyagramlarda örnekler yine trakiandezit alanına düşmüştür.

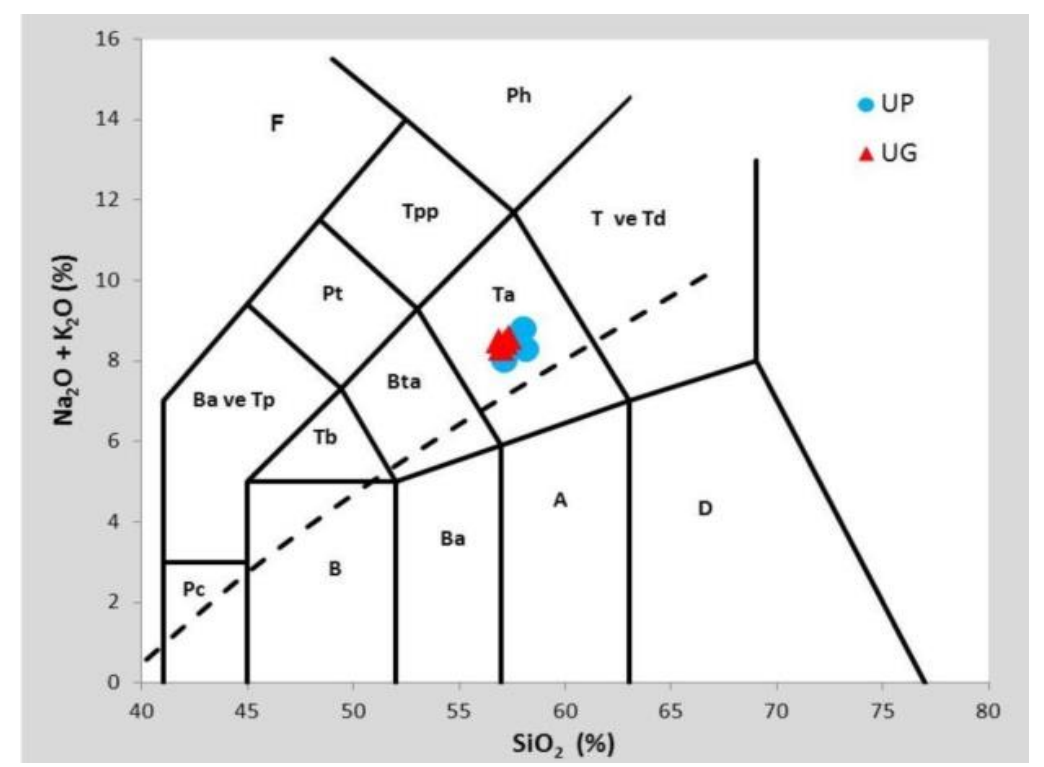

Şekil 5. Toplam alkali-SiO 2 diyagramı (Le Bas ve Le Maitre, 1986) (kesikli çizgi alkali-subalkali ayrımını göstermektedir, (Miyashiro, 1974)), (Bta: Bazaltik trakiandezit, Ta: Trakiandezit, A: Andezit, T ve Td: Trakit\&Trakidasit, D:Dasit, R: Riyolit, Ba: Bazaltik andezit, B: Bazalt, Pc: Pikrobazalti, Tb: Trakibazalt, F: Foidit, Ba ve Tp: Bazanit\&Tefrit, Pt: Fonotefrit, Tpp: Tefrifonolit, Ph: Fonolit).

Tablo 4. Traki ön ekli volkanitlerin $\mathrm{Na}_{2} \mathrm{O}$ ve $\mathrm{K}_{2} \mathrm{O}$ içeriklerine göre alt sınıflandırılması (Le Maitre ,2002)

\begin{tabular}{|l|l|l|l|}
\hline & Trakibazalt & Bazaltik Trakiandezit & Trakiandezit \\
\hline $\mathrm{Na}_{2} \mathrm{O}-\mathrm{K}_{2} \mathrm{O} \geq 2$ & Havaiit & Müjearit & Benmorit \\
\hline $\mathrm{Na}_{2} \mathrm{O}-\mathrm{K}_{2} \mathrm{O} \leq 2$ & Potasik Trakibazalt & Şoşonit & Latit \\
\hline
\end{tabular}




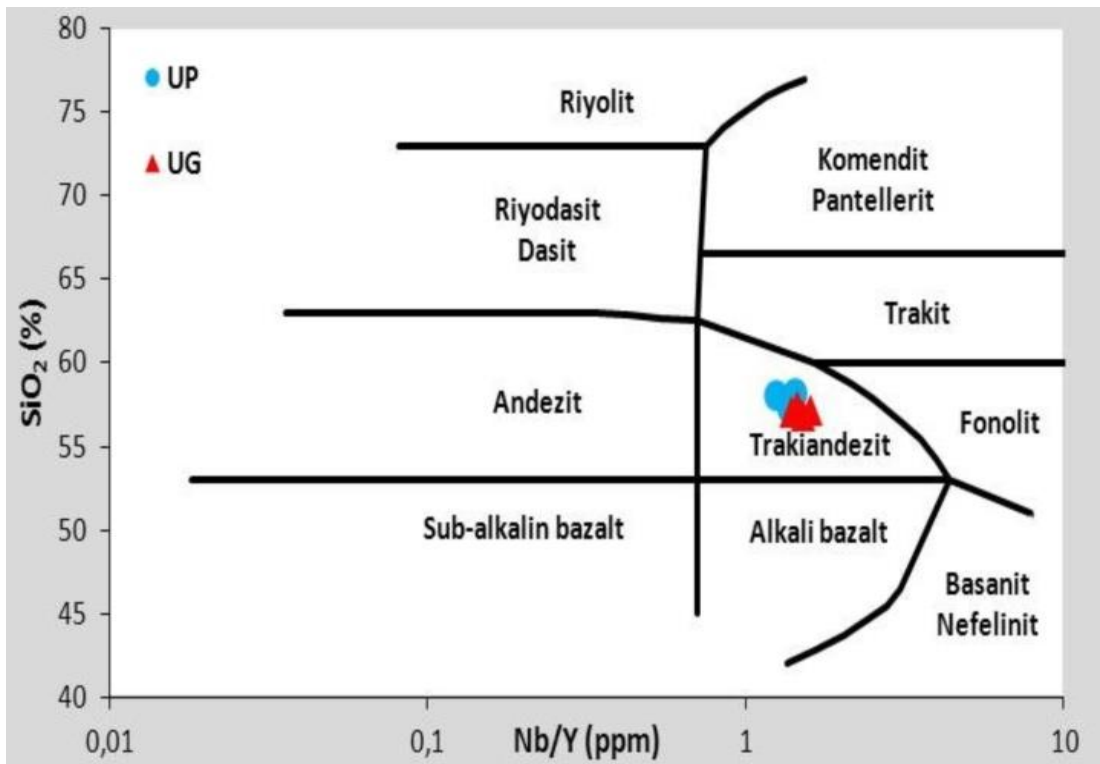

Şekil 6. UG ve UP $\mathrm{SiO}_{2}$ 'ye karşı Nb/Y diyagramı (Winchester ve Floyd 1978)

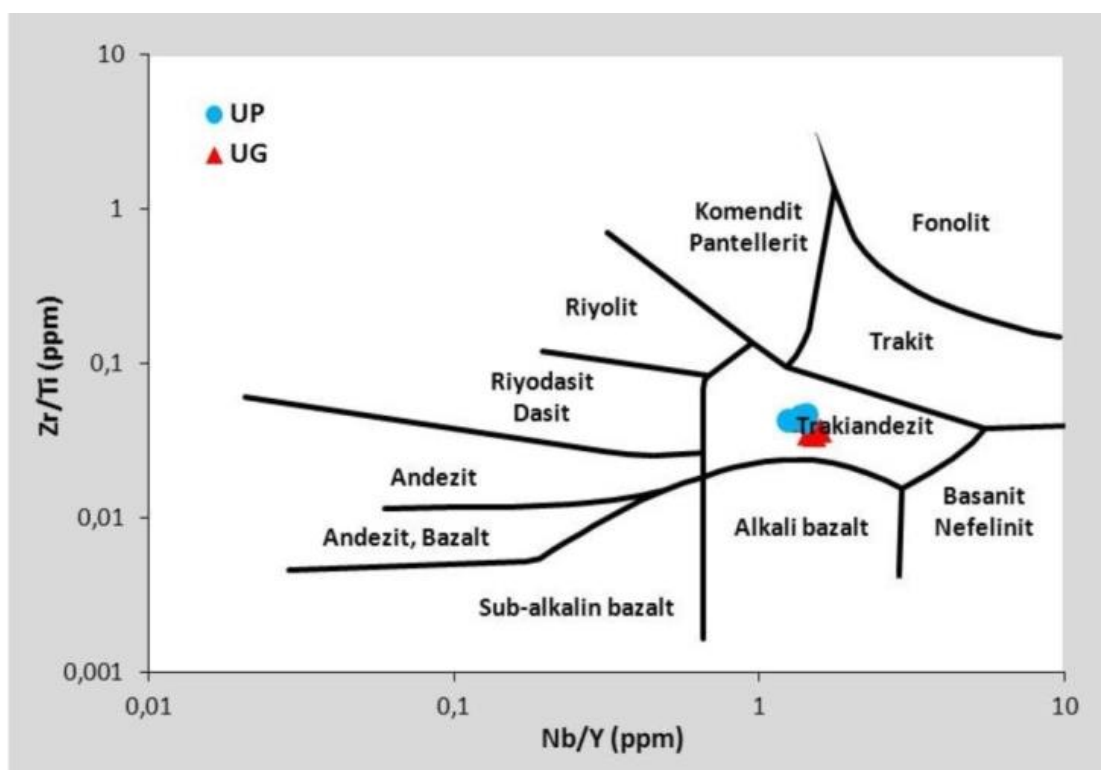

Şekil 7. Zr/Ti diyagramı (Winchester ve Floyd 1978)

\section{Kayacın fiziko-mekanik özellikleri}

Kayacın fiziko-mekanik özelliklerini belirlemek için Tablo 2 'de belirtilen deney metodları ve numune miktarı kullanılmıştır. Kayaca ait belirlenen özellikler Tablo 5'de verilmiştir. Elde edilen verilerin istatiksel çalışmaları (minimum $\left(X_{\text {min. }}\right)$, maksimum $\left(X_{\text {mak. }}\right)$, ortalama $\left(X_{\text {ort. }}\right)$, standart sapma (S), varyans (V)) yapılmıştır. 
Tablo 5. Trakiandezitlerin fiziko-mekanik özellikleri

\begin{tabular}{|c|c|c|c|c|c|c|}
\hline Gerçek Yoğunluk $\left(\mathrm{kg} / \mathrm{m}^{3}\right)$ & $\mathrm{n}$ & $X_{\min }$ & $\mathrm{X}_{\max }$ & $X_{\text {ort }}$ & $S$ & $\mathrm{~V}$ \\
\hline UG & 6 & 2699 & 2705 & 2702 & 0.002 & 0.00 \\
\hline UP & 6 & 2698 & 2702 & 2700 & 0.002 & 0.00 \\
\hline Toplam Gözeneklilik (\%) & $\mathrm{n}$ & $\mathrm{X}_{\min }$ & $\mathrm{X}_{\max }$ & $\mathrm{X}_{\text {ort }}$ & $\mathrm{S}$ & $\mathrm{V}$ \\
\hline UG & 6 & 13.77 & 19.27 & 17.51 & 2.26 & 5.12 \\
\hline UP & 6 & 15.62 & 17.60 & 16.55 & 0.59 & 0.35 \\
\hline Görünür Yoğunluk $\left(\mathrm{kg} / \mathrm{m}^{3}\right)$ & $\mathrm{n}$ & $\mathrm{X}_{\min }$ & $\mathrm{X}_{\max }$ & $\mathrm{X}_{\text {ort }}$ & $\mathrm{S}$ & $\mathrm{V}$ \\
\hline UG & 6 & 2150 & 2.510 & 2.360 & 0.13 & 0.02 \\
\hline UP & 6 & 2006 & 2220 & 2140 & 0.04 & 0.00 \\
\hline Açık Gözeneklilik (\%) & $\mathrm{n}$ & $\mathrm{X}_{\min }$ & $\mathrm{X}_{\max }$ & $\mathrm{X}_{\text {ort }}$ & $\mathrm{S}$ & $\mathrm{V}$ \\
\hline UG & 6 & 0.76 & 0.87 & 0.82 & 0.039 & 0.00 \\
\hline UP & 6 & 0.82 & 0.91 & 0.88 & 0.037 & 0.00 \\
\hline $\begin{array}{l}\text { Atmosfer Basıncı Altında Su Emme Tayini } \\
\text { (Suya Doygun) (\%) }\end{array}$ & $\mathrm{n}$ & $X_{\min }$ & $X_{\max }$ & $X_{\text {ort }}$ & $S$ & V \\
\hline UG & 8 & 1.10 & 1.26 & 1.20 & 0.05 & 0.00 \\
\hline UP & 8 & 1.25 & 1.43 & 1.33 & 0.05 & 0.00 \\
\hline Basınç Dayanımı Tayini (MPa) & $\mathrm{N}$ & $\mathrm{X}_{\min }$ & $\mathrm{X}_{\max }$ & $X_{\text {ort }}$ & $\mathrm{S}$ & $\mathrm{V}$ \\
\hline UG & 15 & 94.9 & 123.5 & 110.4 & 8.4 & 70 \\
\hline UP & 15 & 81.6 & 99.1 & 90.1 & 4.7 & 22.3 \\
\hline Sabit Moment Altında Eğilme Dayanımı (MPa) & $\mathrm{n}$ & $X_{\min }$ & $\mathrm{X}_{\max }$ & $\mathrm{X}_{\text {ort }}$ & $\mathrm{S}$ & $\mathrm{V}$ \\
\hline UG & 10 & 12.02 & 12.57 & 12.25 & 0.18 & 0.03 \\
\hline UP & 10 & 11.01 & 12.25 & 11.90 & 0.36 & 0.12 \\
\hline Schmidt Sertliği (Geri tepme Sayısı) & $\mathrm{n}$ & $\mathrm{X}_{\min }$ & $\mathrm{X}_{\max }$ & $\mathrm{X}_{\text {ort }}$ & $\mathrm{S}$ & $\mathrm{V}$ \\
\hline UG & 50 & 24 & 33 & 28.52 & 2.10 & 4.33 \\
\hline UP & 50 & 20 & 32 & 25.95 & 2.96 & 8.58 \\
\hline $\begin{array}{l}\text { Aşınma Direnci Tayini (Böhme Metodu) } \\
\left(\mathrm{cm}^{3} / 50 \mathrm{~cm}^{2}\right)\end{array}$ & $\mathrm{n}$ & $X_{\text {min }}$ & $\mathrm{X}_{\max }$ & $X_{\text {ort }}$ & $S$ & $\mathrm{~V}$ \\
\hline UG & 6 & 18.02 & 19.08 & 18.44 & 0.49 & 0.21 \\
\hline UP & 6 & 19.95 & 21.30 & 20.67 & 0.50 & 0.22 \\
\hline Darbe Dayanımı (MPa) & $\mathrm{n}$ & $\mathrm{X}_{\min }$ & $\mathrm{X}_{\max }$ & $\mathrm{X}_{\text {ort }}$ & $\mathrm{S}$ & $\mathrm{V}$ \\
\hline UG & 10 & 3.00 & 4.00 & 3.80 & 0.42 & 0.16 \\
\hline UP & 10 & 2.00 & 4.00 & 3.40 & 0.70 & 0.44 \\
\hline Nokta Yükleme (MPa) & $\mathrm{n}$ & $X_{\min }$ & $\mathrm{X}_{\max }$ & $X_{\text {ort }}$ & $\mathrm{S}$ & V \\
\hline UG & 8 & 6.59 & 7.62 & 7.09 & 0.38 & 0.11 \\
\hline UP & 8 & 5.53 & 6.57 & 6.19 & 0.35 & 0.11 \\
\hline Dinamik Elastisite Modülü (GPa) & $\mathrm{n}$ & $X_{\min }$ & $X_{\max }$ & $X_{\text {ort }}$ & $\mathrm{S}$ & V \\
\hline UG & 7 & 2.85 & 3.51 & 3.16 & 0.26 & 0.06 \\
\hline UP & 7 & 3.14 & 3.64 & 3.33 & 0.16 & 0.02 \\
\hline Dinamik Poisson Oranı & $\mathrm{n}$ & $\mathrm{X}_{\min }$ & $\mathrm{X}_{\max }$ & $X_{\text {ort }}$ & $\mathrm{S}$ & V \\
\hline UG & & 0.307 & 0.311 & 0.309 & 0.001 & 0.00 \\
\hline UP & & 0.306 & 0.310 & 0.308 & 0.001 & 0.00 \\
\hline $\begin{array}{l}\text { Termal şok etkisiyle yıpranmaya direncin tayini } \\
\text { (Kütle Değişimi) (\%) (20 çevrim) }\end{array}$ & $\mathrm{n}$ & $X_{\min }$ & $X_{\max }$ & $X_{\text {ort }}$ & S & V \\
\hline UG & 7 & 1.50 & 3.01 & 2.08 & 0.67 & 0.38 \\
\hline UP & 7 & 1.62 & 3.21 & 2.34 & 0.64 & 0.35 \\
\hline
\end{tabular}

\section{SONUÇLAR}

Bu çalışmada Altıntaş köyü (Uşak) kuzeyindeki Karaboldere volkanikleri içerisinde yer alan andezitik kayaçları, petrografik ve kimyasal analizlere göre trakiandezit olarak adlandırılmıştır. Kayaçların fiziko-mekanik özellikleri belirlenerek literatür ve standartlar ışığında değerlendirilmiştir. Kayaçları oluşturan minerallerin aynı olması ve aynı volkanizma ürünü olmasından dolayı kayaçların gerçek yoğunlukları birbirine çok yakındır. 
Fakat UG'nin toplam gözenekliliğin UP'ye göre düşük olması kayacın basınç dayanımı, eğilme dayanımı, su emme oranı gibi diğer özelliklerinin UP kayacına göre daha iyi değerlere sahip olmasında rol oynamaktadır. Deere DU, Miller (1966)'e göre basınç dayanımlarına göre UP orta mukavemetli, UG çok mukavemetli kaya sınıfında yer almaktadır.

Schmidt çekici geri sıçrama sınıfına göre kaya sertliği az sert kayaç olarak tanımlanabilir (ISRM, 1978). ÇaIışmanın konusunu oluşturan kayaçlar, kaplama ve döşeme taşı olarak kullanılabilirliği TS 10835 (1993)'e göre irdelendiğinde kaplama ve yer döşeme olarak kullanılan andezitlerin özkütlesinin $2.55 \mathrm{gr} / \mathrm{cm}^{3}$ den büyük olması istenir. TS 10835 (1993)'e göre döşeme ve kaplama taşı olarak kullanılacak kayaçların tek eksenli basınç dayanımı döşeme> $98.06 \mathrm{MPa}$ kaplama $>58.84$ $\mathrm{MPa}$, eğilme dayanımının döşeme>7.85MPa kaplama>5.88 MPa sürtünme kaybının hacimce döşeme> 17 kaplama $>28 \mathrm{~cm}^{3} / 50 \mathrm{~cm}^{2}$ olması beklenmektedir. Bu sınır değerlere göre Tablo 5'deki kayaçlara ait veriler değerlendirildiğinde her iki kayaç (UG ve UP) kaplama taşı olarak kullanılabilmektedir.

\section{KAYNAKLAR}

Brown, E.T., (1981). Rock Characterization, Testing and Monitoring - ISRM Suggested Method., Oxford, Pergamon Press.

Deere, D.U., Miller, R.P., (1978). Classification and Indeks Properties of Intact Rock. Tech. Report AFWLTR-65-116, AF Special Weapons Center, Kirkland Air Force Base, New Mexico. 1966.

Ercan, T., Dinçel, A., Metin, S., Türkecan, A., Günay, E., (1978). Uşak Yöresindeki Neojen Havzalarının Jeolojisi. TJK Bülteni, 21(2), 95-97.

Ercan, T., Dinçel, A., (1980). 1/50.000 ölçekli Türkiye Jeoloji Haritası Serisi Uşak-K22-c paftası. Maden Tetkik ve Arama Genel Müdürlüğü yayını, Ankara

Hart, S.R., Erlant, A.J., Kable, E.J.D., (1974). Sea Floor Basalts Alteration: Some Chemical and Sr Isotopic Effects. Contributions to Mineralogy and Petrology, 44, 219-230.

Humphris, S.E., Morrison, M.A., Thompson, R.N., (1978). Influence of Rock Crystallization History Upon Subsequent Lantharide Mobility During Hydrothermal Alteration of Basalts. Chemical Geology, 28, 125-137.

International Rock Mechanics and Mining Sciences (ISRM), (1978). Suggested Methods for Determining Hardness and Abrasiveness of Rocks. 15, 89- 97.

İC Danışmanlık ve Eğitim, (2014). Doğal Taş ve Mermer Sektörü Kümesi İhtiyaç Analizi ve Sektör Stratejisi Raporu. 95. 